

\title{
Effects of high-intensity training on muscle lactate transporters and postexercise recovery of muscle lactate and hydrogen ions in women
}

\author{
David Bishop, ${ }^{1,2}$ Johann Edge, ${ }^{3}$ Claire Thomas, ${ }^{4,5}$ and Jacques Mercier ${ }^{4,6}$ \\ ${ }^{1}$ School of Human Movement and Exercise Science, The University of Western Australia, Crawley, Western Australia, \\ Australia; ${ }^{2}$ Facoltà di Scienze Motorie, Università degli Studi di Verona, Verona, Italy; ${ }^{3}$ Institute of Food, Nutrition, \\ and Human Health, Massey University, Palmerston North, New Zealand; ${ }^{4}$ EA 701, Unité de Formation et de Recherche \\ Médecine, Université Montpellier 1, ${ }^{6}$ Institut National de la Santé et de la Recherche Médicale, ERI 25, Montpellier; \\ and ${ }^{5}$ Université Evry Val d'Essonne, Unité de Formation et de Recherche Sciences Fondamentales et Appliquées, \\ Evry, France
}

The purpose of this study was to investigate the effects of highintensity interval training (3 days/wk for $5 \mathrm{wk}$ ), provoking large changes in muscle lactate and $\mathrm{pH}$, on changes in intracellular buffer capacity $\left(\mathrm{j}^{3} \mathrm{~m}_{\text {in vitro }}\right)$, monocar- boxylate transporters (MCTs), and the decrease in muscle lactate and hydrogen ions $\left(\mathrm{H}^{+}\right)$after exercise in women. Before and after train- ing, biopsies of the vastus lateralis were obtained at rest and imme- diately after and $60 \mathrm{~s}$ after $45 \mathrm{~s}$ of exercise at $190 \%$ of maximal $\mathrm{O}_{2}$ uptake. Muscle samples were analyzed for ATP, phosphocreatine (PCr), lactate, and $\mathrm{H}^{+}$; MCT1 and MCT4 relative abundance and $\mathrm{j} 3 \mathrm{~m}_{\mathrm{in}}$ vitro were also determined in resting muscle only. Training provoked a large decrease in postexercise muscle $\mathrm{pH}(\mathrm{pH}$ 6.81). After training, there was a significant decrease in $\mathrm{j} 3 \mathrm{~m}_{\text {in vitro }}(-11 \%)$ and no significant change in relative abundance of MCT1 $(96+12 \%)$ or MCT4 $(120+21 \%)$. During the 60 -s recovery after exercise, training was associated with no change in the decrease in muscle lactate, a significantly smaller decrease in muscle $\mathrm{H}^{+}$, and increased $\mathrm{PCr}$ resynthesis. These results suggest that increases in $\mathrm{j} 3 \mathrm{~m}_{\text {in vitro and MCT }}$ relative abundance are not linked to the degree of muscle lactate and $\mathrm{H}^{+}$accumulation during training. Furthermore, training that is very intense may actually lead to decreases in $j 3 \mathrm{~m}_{\text {in vitro. The smaller }}$ postexercise decrease in muscle $\mathrm{H}^{+}$after training is a further novel finding and suggests that training that results in a decrease in $\mathrm{H}^{+}$ accumulation and an increase in $\mathrm{PCr}$ resynthesis can actually reduce the decrease in muscle $\mathrm{H}^{+}$during the recovery from supramaximal exercise.

buffer capacity; monocarboxylate transporter 1; monocarboxylate transporter 4; phosphocreatine resynthesis; females

REMOVAL OF HYDROGEN IONS $\left(\mathrm{H}^{+}\right)$during intense skeletal muscle contractions occurs via intracellular buffering and via a number of different transport systems (27). The intracellular buffer capacity $\left(j 3 \mathrm{~m}_{\text {in vitro }}\right)$ measures the contribution to physicochemical buffering by proteins, dipeptides (e.g., carnosine), and phosphates within the muscle but excludes "dynamic" metabolic buffering, such as the rephosphorylation of ADP by phosphocreatine (PCr). Sarcolemmal transporters also have an important role in the regulation of intracellular $\mathrm{pH}$ during high-intensity exercise (29). In particular, lactate- $\mathrm{H}^{+}$cotrans-

Address for reprint requests and other correspondence: D. Bishop, Facoltà di Scienze Motorie, Università degli Studi di Verona, via Casorati 43, Verona I-37131, Italy (e-mail: David.Bishop@univr.it). port during exercise is largely mediated by monocarboxylate transporters (MCTs), which are stereoselective for L-(+)-lactate and dependent on the $\mathrm{pH}$ gradient (29). Although 14 MCTs are known to exist, lactate- $\mathrm{H}^{+}$cotransport in skeletal muscle is attributed to two isoforms (MCT1 and MCT4) (29, 38, 51). Although both $\mathrm{j} 3 \mathrm{~m}_{\text {in vitro }}(13,14,43)$ and MCT1 and MCT4 (6, $11,30)$ have been reported to be altered in response to certain types of exercise training, little is known about the stimulus for such muscle adaptations.

The local formation of $\mathrm{H}^{+}$and/or lactate within the skeletal muscle during exercise has been proposed to be an important stimulus for adaptations of the muscle $\mathrm{pH}$-regulating systems $(13,31,50)$. There is some support for this hypothesis, as $\mathrm{j} 3 \mathrm{~m}_{\mathrm{in}}$ vitro has been reported to increase in response to highintensity, but not moderate-intensity, training (14). In addition, Hashimoto et al. (23) recently reported that the addition of lactate anions to a tissue culture can increase the expression of MCT1 mRNA and protein in L6 cells. However, in vivo, greater accumulation of lactate and $\mathrm{H}^{+}$during training has not always been shown to be associated with greater increases in MCT relative abundance $(31,35)$.

An important difference between in vivo and tissue culture studies is that, in vivo, lactate production occurs concurrently with the formation of $\mathrm{H}^{+}(25,42)$. Furthermore, research suggests that too large an accumulation of $\mathrm{H}^{+}$during training may have a detrimental effect on adaptations to the $\mathrm{pH}$ regulatory systems within the muscle $(15,47)$. Recent findings from our laboratory have shown that, despite being matched for training intensity and total work performed, interval training with short (1-min) rest periods (end-exercise $\mathrm{pH}$ ?6.81) resulted in a consistent decrease in $j 3 \mathrm{~m}_{\text {in vitro, whereas interval }}$ training with longer (3-min) rest periods (end-exercise $\mathrm{pH}$ 36.90) resulted in a consistent increase in $\mathrm{j} 3 \mathrm{~m}_{\text {in vitro }}$ (15). In addition, decreasing the $\mathrm{H}^{+}$accumulation during interval training (via sodium bicarbonate ingestion) results in significantly greater improvements in MCT4 relative abundance in rats (47). Therefore, we hypothesized that, similar to our previous findings for $\mathrm{j} 3 \mathrm{~m}_{\text {in vitro, high-intensity interval training interspersed }}$ with short rest periods, inducing a low muscle $\mathrm{pH}$, may not increase MCT relative abundance.

If the local formation of $\mathrm{H}^{+}$and/or lactate within the skeletal muscle during exercise is an important stimulus for adaptations 
of the muscle pH-regulating systems $(13,31,50)$, one might also expect that high-intensity training, inducing a low muscle $\mathrm{pH}$, might lead to a greater decrease in muscle lactate and $\mathrm{H}^{+}$ after intense exercise. However, although many studies have measured changes in blood lactate after different forms of endurance training, we are aware of few studies that have reported changes in muscle lactate and $\mathrm{H}^{+}$during the recovery from intense exercise $(35,43)$. Interpretation of these previous findings is compromised by the methodological approach taken, in that muscle biopsies were obtained after more work was performed (and greater changes in metabolites were produced) after training. Furthermore, these studies measured muscle metabolite changes after 3-5 min of recovery, and we are aware of no previous studies that have investigated more rapid (i.e., :S1-min) changes in muscle metabolites during the recovery from intense exercise.

The aim of this study, therefore, was to investigate postexercise recovery of lactate and $\mathrm{H}^{+}$and changes in $\mathrm{j} 3 \mathrm{~m}_{\mathrm{in}}$ vitro and MCTs after high-intensity interval training (3 days/wk for 5 wk). As the accumulation of $\mathrm{H}^{+}$has been shown to affect oxidative phosphorylation, enzyme activity, and ion regulation during some exercise tasks $(18,26,44,46)$, it is important to understand the stimuli responsible for training-induced changes in factors that regulate $\mathrm{H}^{+}$accumulation during and after exercise. A secondary aim was to investigate changes in MCT relative abundance in women after training, as we are aware of only one study that has recruited women (17), and this study recruited elite, cross-country skiers. We hypothesized that high-intensity interval training, inducing a low muscle $\mathrm{pH}$, would not increase $j 3 \mathrm{~m}_{\text {in vitro, }}$ MCT relative abundance, or the decline in muscle lactate and $\mathrm{H}^{+}$during the recovery from intense exercise.

\section{METHODS}

\section{Subjects}

Six active, female, sport science students $[20+2$ yr of age, $63.9+$ $7.8 \mathrm{~kg}$ body mass, $43.2+4.9 \mathrm{ml} \cdot \mathrm{kg}^{-1} \cdot \mathrm{min}^{-1}$ maximal $\mathrm{O}_{2}$ uptake $\left.\left(\dot{\mathrm{V}}_{2 \max }\right)\right]$ volunteered to participate in the study. Each subject was involved in an intermittent sport (hockey, netball, tennis, basketball, or football) at club level (1-2 training sessions per week plus 1 competition). Subjects were informed of the study requirements, benefits, and risks before giving written informed consent. Approval for the study procedures was granted by the Institutional Research Ethics Committee.

\section{Experimental Overview}

An overview of the experiment is shown in Fig. 1. All subjects completed a familiarization trial for all tests before the start of the study. During pre- and posttraining testing, each subject performed a graded exercise test (GXT) and a 45-s constant-intensity exercise test $\left(190 \% \dot{V}_{\text {O2max }}, \mathrm{CIT}_{45}\right)$; in addition, a muscle biopsy from the vastus lateralis muscle was obtained at rest, immediately after the $\mathrm{CIT}_{45}$, and $60 \mathrm{~s}$ after the $\mathrm{CIT}_{45}$. After the pretesting period, subjects performed supervised, high-intensity interval training $(6-12,2$-min intervals at $100 \% \dot{\mathrm{V}}_{\mathrm{O}_{2 \max }}$, with $1 \mathrm{~min}$ of rest between intervals) 3 days/wk for 5 wk. Pre- and posttraining tests were conducted at the same time of day. Subjects were asked to maintain their normal diet and training throughout the study. They were also required to consume no food or beverages (other than water) $2 \mathrm{~h}$ before testing and were asked not to consume alcohol or perform vigorous exercise in the $24 \mathrm{~h}$ before testing. Each subject was asked to record food and fluid consumption 2 days before each test and to replicate this food and fluid consumption during posttraining testing.

\section{GXT}

A GXT was performed on an air-braked track-cycle ergometer (Evolution, Adelaide, Australia) for determination of $\dot{\mathrm{V}}_{\mathrm{O} 2 \mathrm{max}}$ and the lactate threshold. For the test, which consisted of graded exercise steps (4-min stages), we used an intermittent protocol (with 1-min break between stages). The GXT commenced at $50 \mathrm{~W}$, and, thereafter, intensity was increased by $30 \mathrm{~W}$ every 4 min until volitional exhaustion (4).

\section{Gas Analysis During the GXT}

During the GXT, expired air was continuously analyzed for $\mathrm{O}_{2}$ and $\mathrm{CO}_{2}$ concentrations with use of Ametek gas analyzers (models SOV S-3A11 and COV CD-3A, Applied Electrochemistry, Pittsburgh, PA). Ventilation was recorded every $15 \mathrm{~s}$ using a turbine ventilometer (model 225A, Morgan, Kent, UK). The gas analyzers were calibrated immediately before and verified after each test with use of three certified gravimetric gas mixtures (BOC Gases, Chatswood, Australia); the ventilometer was calibrated before exercise and verified after exercise with use of a 1-liter syringe in accordance with the manufacturer's instructions. The ventilometer and gas analyzers were connected to an IBM personal computer, which measured and displayed variables every $15 \mathrm{~s}$. The sum of the two highest consecutive 15 -s values was recorded as the subject's $\dot{V}_{O_{2} \max }$

\section{$\mathrm{CIT}_{45}$}

The high-intensity cycle test consisted of $45 \mathrm{~s}$ of continuous cycling at a set power output $(395+47 \mathrm{~W})$ on an air-braked, frontaccess cycle ergometer (model Ex-10, Repco, Mulgrave, Victo- ria, Australia). Toe clips and heel straps were used to secure the feet to the pedals, and the test was performed in the seated position. Strong verbal encouragement was provided to each subject during the test. On the basis of pilot work, the power output for the CIT 45 was $190 \%$ of the mean power output at $\dot{\mathrm{VO}}_{2 \max }$ (to enable a workload that was severe but could be completed by all subjects).

\section{Training Intervention}

Within 4-7 days of baseline testing, subjects began a high-intensity interval-training program $\left(6-12,2\right.$-min intervals at $100 \% \dot{\mathrm{V}} \mathrm{O}_{2 \max }$, with $1 \mathrm{~min}$ of rest between sets). The subjects performed three training sessions per week (Monday, Wednesday, Friday) for 5 consecutive weeks. All training sessions were completed on mechanically braked cycle ergometers (model 818E, Monark, Stockholm, Sweden) and were preceded by a 5 -min warm-up at $50 \mathrm{~W}$. Progression was controlled by increasing the workload (by altering the resistance) and the number of intervals performed in a training session. Training programs followed a periodized plan (session-to-session of altering training volume) so as to simulate athletic training programs, allow progression, and prevent overtraining. Pilot work performed on five subjects not involved in the present study (recruited from the same
Fig. 1. Experimental overview. GXT, graded exercise test; $\mathrm{CIT}_{45}, 45$-s constant-intensity (190\% maximal $\mathrm{O}_{2}$ uptake) exercise test. Muscle biopsies were obtained at arrows.

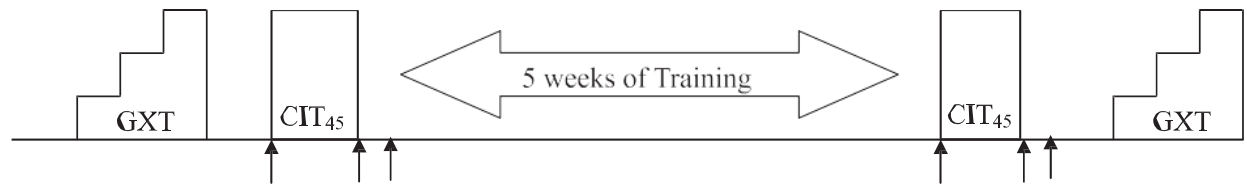


population) revealed that muscle $\mathrm{H}^{+}$concentration $\left(\left[\mathrm{H}^{+}\right]\right) 1 \mathrm{~min}$ after the sixth interval of a typical interval training session was $155+15$ $\mathrm{nmol} / \mathrm{l}(\mathrm{pH} 6.81)$.

\section{Capillary Blood Sampling and Heart Rate}

Glass capillary tubes were used to collect $50 \mu \mathrm{l}$ of blood during the GXT (D957G-70-35, Clinitubes, Radiometer Copenhagen) and 100 $\mu \mathrm{l}$ of blood during the $\mathrm{CIT}_{45}$ (D957G-70-125, Clinitubes). A hyperemic ointment (Finalgon, Boehringer Ingelheim) was applied to the earlobe 5-7 min before initial blood sampling. Capillary blood samples were taken at rest and immediately after each 4-min stage of the GXT for the determination of the lactate threshold [using the modified $D_{\max }$ method (4)]. Capillary blood samples were also taken at rest, immediately after the $\mathrm{CIT}_{45}$, and 3 and 5 min after the $\mathrm{CIT}_{45}$. Blood $\mathrm{H}^{+}$and lactate concentrations were determined using a blood-gas analyzer (ABL 625, Radiometer Copenhagen). The blood-gas analyzer was regularly calibrated using precision standards and routinely assessed by external quality controls.

\section{Muscle Sampling and Analysis}

On the day of the $\mathrm{CIT}_{45}$, local anesthesia [5 ml, $1 \%$ lidocaine (Xylocaine)] was administered, and two incisions were made into the vastus lateralis of each subject. The first incision was used for the resting biopsy, and the second was closed with a Steri-Strip and subsequently used for the biopsies taken after exercise; manual suction was applied for all samples. The first muscle sample was taken (before warm-up) during supine rest. Samples (50-80 mg) were also taken immediately after cessation of the $\mathrm{CIT}_{45}$ (while the subject remained on the cycle ergometer) and $60 \mathrm{~s}$ later. The samples were quickly removed from the biopsy needle and immediately stored at $-80^{\circ} \mathrm{C}$ until subsequent analysis. Freeze-dried muscle was dissected free from visible blood, fat, and connective tissue.

\section{Muscle ATP, PCr, and Lactate}

Freeze-dried rest and postexercise muscle samples (3-5 mg) were enzymatically assayed for ATP, PCr, and lactate. ATP, PCr, and lactate were extracted from muscle samples by the addition of $6 \%$ perchloric acid before centrifugation $(10,000 \mathrm{~g}$ for $10 \mathrm{~min})$. The supernatant was removed and neutralized by the addition of $2.4 \mathrm{~mol} / \mathrm{l}$ $\mathrm{KOH}$ and $3 \mathrm{~mol} / \mathrm{l} \mathrm{KCl}$. Samples were centrifuged again, and the supernatant was stored at $-80^{\circ} \mathrm{C}$. ATP, $\mathrm{PCr}$, and lactate were measured using a previously described method (1).

\section{Muscle Buffering Capacity: Titration Method $\left(\mathrm{J}^{3} m_{\text {in }}\right.$ vitro $)$ and $\left[\mathrm{H}^{+}\right]$}

Freeze-dried, resting muscle samples (1.8-2.5 mg) were homogenized on ice for $2 \mathrm{~min}$ in a solution containing $\mathrm{NaF}(10 \mathrm{mM})$ at a dilution of $30 \mathrm{mg}$ dry muscle/ml homogenizing solution. The muscle homogenate was placed in a circulating water bath at $37^{\circ} \mathrm{C}$ for $5 \mathrm{~min}$ before and during $\mathrm{pH}$ measurement. The $\mathrm{pH}\left(\left[\mathrm{H}^{+}\right]\right)$was measured with a microelectrode (model MI-415, Microelectrodes, Bedford, NH) connected to a pH meter (model SA 520, Orion Research, Cambridge, MA). After initial pH measurement, muscle homogenates (rest samples) were adjusted to $\mathrm{pH} \geqslant 7.2$ with an $\mathrm{NaOH}(0.02 \mathrm{M})$ solution and then titrated to $\mathrm{pH}$ ? 6.2 by the serial addition of $2 \mu \mathrm{l}$ of $\mathrm{HCl}(10 \mathrm{mM})$. From the fitted titration trendline, the amount of $\mathrm{H}^{+}(\mathrm{mol} / \mathrm{kg}$ dry muscle) required to change $\mathrm{pH}$ from 7.1 to 6.5 was interpolated. This value was then normalized to the whole $\mathrm{pH}$ unit for final display as millimoles of $\mathrm{H}^{+}$per kilogram of dry muscle per unit of $\mathrm{pH}$ and determined as the subject's $j 3 \mathrm{~m}_{\text {in }}$ vitro.

\section{Sample Preparation for Western Blotting}

Proteins were isolated from resting muscle samples for Western blotting by a standard method previously described by McCullagh et al. (34) and previously used in our laboratory (48). Muscle protein concentrations were determined in duplicate by bicinchoninic acid assay (Pierce, Interchim, Montluçon, France) with the use of BSA as a standard. There was no significant difference in the concentration of protein isolated from pre- and posttraining resting muscle samples $(3.6+0.9$ vs. $3.4+0.8 \mathrm{~g} / \mu \mathrm{l}, P>0.05)$.

\section{Western Blotting of MCT1 and MCT4}

MCT abundance was determined using previously described methods (34). Human antibodies specified for MCT1 and MCT4 detection resulted from specific antigens produced with synthetic peptides against the $\mathrm{COOH}$-terminal region of MCT1 and MCT4, respectively, linked with their cysteine residue at KLH EDC-activated carrier protein. These antibodies were injected in solutions for immunization of New Zealand White rabbits. Polyclonal antibodies yielded a single band on a Western blot that corresponded to $43 \mathrm{kDa}$, consistent with the molecular mass reported previously (34). Human antibody specificities were confirmed in preliminary experiments in which the peptides blocked the detection of MCT1 and MCT4 (48). Membranes were washed as previously described, and MCT1 or MCT4 expression was detected by enhanced chemiluminescence (Biomax MR films, Kodak, Reuil-Malmaison, France). Films were developed and processed using a hyperprocessor (model RNP 1700, Amersham, Les Ulis, France). MCT1 and MCT4 protein band densities were determined by scanning the blots on a scanner (Duo Scan T1200, AGFA, New York, NY) with Scion Image software (Scion, Frederick, MD). Results are expressed in arbitrary optical density units, as used by others (48).

\section{Citrate Synthase Activity}

Homogenates for citrate synthase (CS) activity were prepared in buffer consisting of (mM) 210 sucrose, 2 EGTA, $40 \mathrm{NaCl}, 30 \mathrm{HEPES}$, 5 EDTA, and 2 PMSF (pH 7.4) and stored at $-80^{\circ} \mathrm{C}$. CS activity was assayed by a spectrophotometric method according to Srere (45). Changes in absorbance were recorded over $3 \mathrm{~min}$ at $412 \mathrm{~nm}$ and at $25^{\circ} \mathrm{C}$.

\section{Statistical Analysis}

Values are means + SD. One-way ANOVA, with repeated mea-

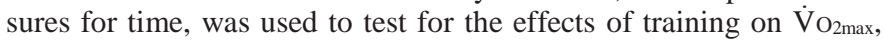
the lactate threshold, MCT content, and muscle buffer capacity. Two-way ANOVA, with repeated measures for time, was used to test for the effects of training on muscle and blood metabolites. Leastsquares linear regression analysis was used to calculate correlation coefficients between measured variables using Pearson's product moment $(r)$. Selected correlation coefficients were also reexamined by the use of semipartial correlations to adjust for the contribution of possible confounding variables. Sigma Stat software (Jandel Scientific, San Rafael, CA) was used for all statistical analyses, and the level of statistical significance was set at $P<0.05$.

\section{RESULTS}

\section{Aerobic Fitness}

There were no significant changes in body mass following training $(63.9+7.8$ vs. $64.0+7.5 \mathrm{~kg})$. There were significant improvements in $\dot{\mathrm{V}}_{2 \max }(43.2+4.9$ vs. $47.4+3.9$ $\left.\mathrm{ml} \cdot \mathrm{kg}^{-1} \cdot \mathrm{min}^{-1},+9.7 \%, P<0.05\right)$, power at $\dot{\mathrm{V}}_{2 \max }(210+$ 20 vs. $231+18 \mathrm{~W},+10.0 \%, P<0.05)$, and lactate threshold $(140+16$ vs. $158+19 \mathrm{~W},+12.9 \%, P<0.05)$. The increase in power at $\dot{\mathrm{V}}_{\mathrm{O} 2 \mathrm{max}}$ after training resulted in a decrease in the relative intensity of the $\mathrm{CIT}_{45}$ from $190 \%$ (before training) to $170 \%$ (after training) of the power at $\dot{V}_{\text {O2max. There was no }}$ significant change in CS activity with training $(35.1+5.3$ vs. $37.1+7.1 \mu \mathrm{mol} / \mathrm{min}, P>0.05)$. 


\section{$\mathrm{J} m_{\text {in vitro }}$ and MCT Relative Abundance}

Individual changes in $\mathrm{j} 3 \mathrm{~m}_{\text {in vitro }}$ (along with mean values) are shown in Fig. 2. Very high-intensity training was associated with a significant decrease $(-11 \%)$ in j3min vitro (from $145.7+$ 6.6 to $129.6+7.7 \mathrm{mmol} \mathrm{H} \mathrm{H}^{+} \cdot \mathrm{kg}$ dry $\left.\mathrm{wt}^{-1} \cdot \mathrm{pH}^{-1}, P<0.05\right)$. After training, there was no significant change in relative abundance of MCT1 $(96+12 \%)$ or MCT4 $(119+21 \%)$, expressed relative to pretraining values. There was a significant correlation between CS activity and relative abundance of MCT1 $(r=0.75, P<0.05)$, but not MCT4 $(r=0.28, P>0.05)$.

\section{Muscle Metabolites}

At rest. Muscle metabolite data measured before and after the 45-s cycle test before and after training are summarized in Fig. 3. Resting muscle ATP, $\mathrm{PCr}$, lactate, and $\mathrm{H}^{+}$concentrations were not signifi different after training $(P>0.05)$.

After high-intensity exercise. There were significant changes in muscle ATP, $\mathrm{PCr}$, lactate, and $\mathrm{H}^{+}$from rest to after exercise before and after training. However, muscle lactate and $\mathrm{H}^{+}$ accumulation after exercise was lower after than before training $(P<0.05)$. A significant correlation was observed between muscle lactate and $\mathrm{H}^{+}$accumulation after exercise when preand posttraining data were pooled (lactate $=0.90 \cdot\left[\mathrm{H}^{+}\right]+81$, $r=0.88, P<0.05, n=12)$. There was no significant change in postexercise ATP or PCr after training $(P>0.05)$ compared with before training. Muscle ATP and PCr measured $60 \mathrm{~s}$ after exercise were significantly higher after training than at the same time point before training, whereas muscle lactate and $\mathrm{H}^{+}$accumulation was significantly lower.

After training, there was no significant change in the decrease in muscle lactate during the first $60 \mathrm{~s}$ of recovery $(14.9+6.4$ vs. $14.8+4.4 \mathrm{mmol} / \mathrm{kg}$ dry wt, $P=0.16)$. In contrast, there was a significantly smaller decrease in muscle $\mathrm{H}^{+}$during the first $60 \mathrm{~s}$ of recovery following training $(25.7+$ 5.2 vs. $17.8+8.9 \mathrm{nmol} / 1, P<0.05)$. This is equivalent to an increase in $\mathrm{pH}$ during the first $60 \mathrm{~s}$ of recovery of $0.09+0.02$ and $0.07+0.02 \mathrm{pH}$ unit before and after training, respectively. There was a significant correlation between the postexercise $\mathrm{H}^{+}$and the decrease in $\mathrm{H}^{+}(r=0.78, P<0.05$; Fig. 4). There was no significant correlation between the decrease in muscle

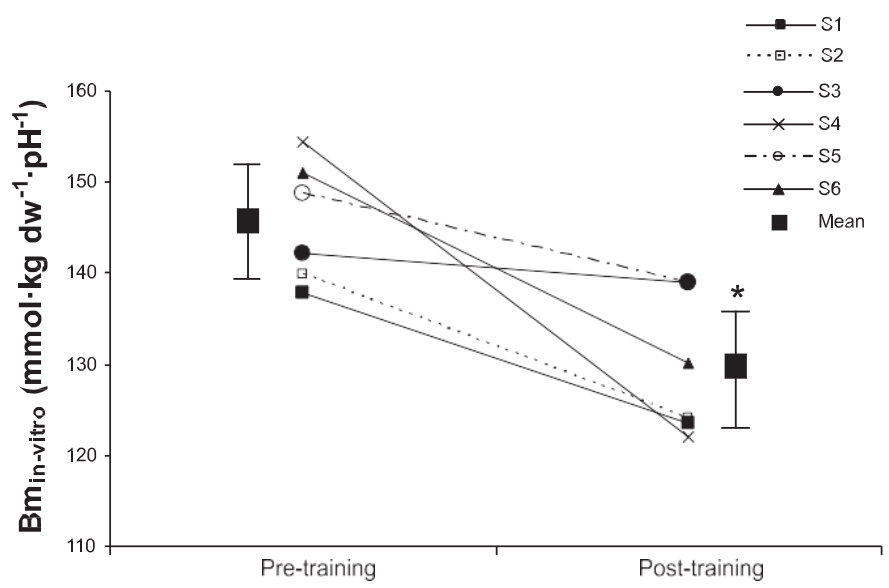

Fig. 2. Individual changes in titrated muscle buffer capacity $\left(j 3 m_{\text {in vitro }}\right)$ in resting skeletal muscle biopsies from untrained women $(S 1-S 6)$ before and after 5 wk of very high-intensity interval training. Values are means + SD. $* P<0.05$ vs. pretraining mean.

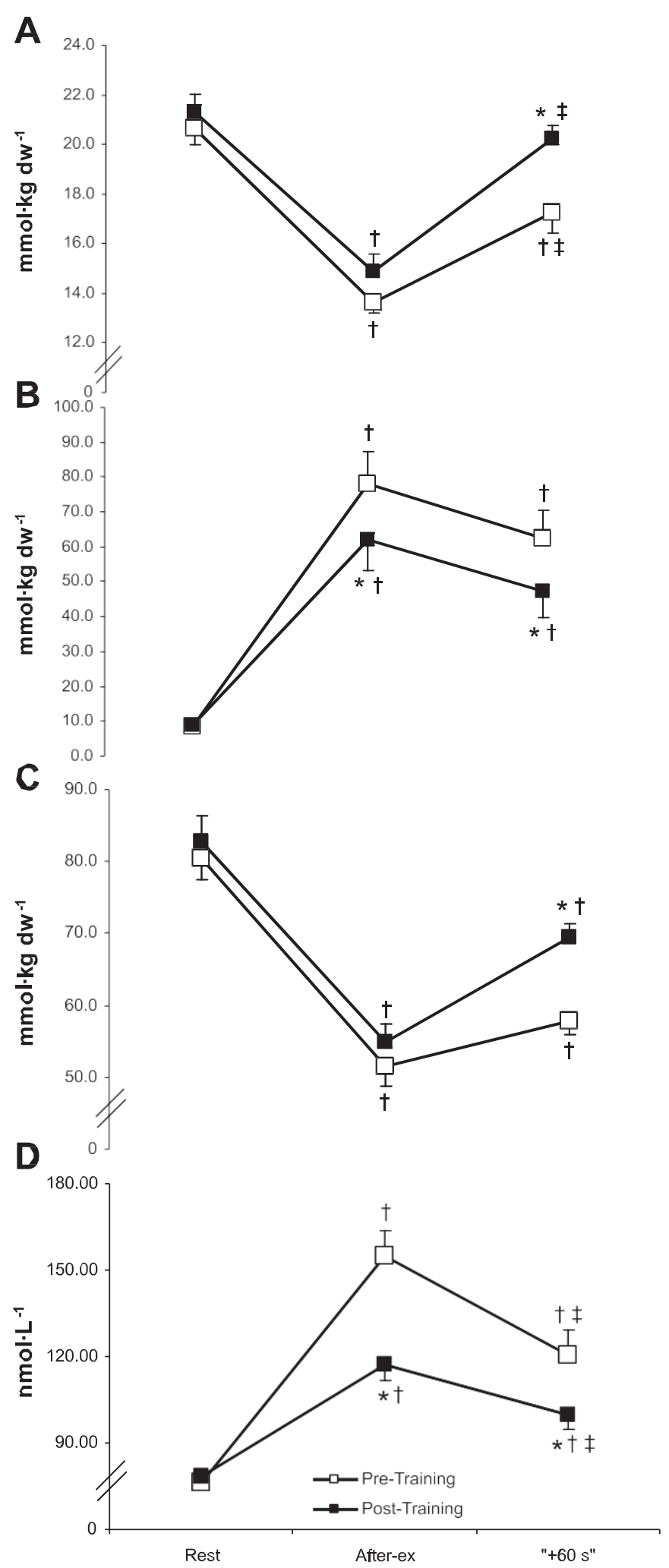

Fig. 3. Muscle ATP $(A)$, lactate $(B)$, phosphocreatine $(\mathrm{PCr}, C)$, and $\mathrm{H}^{+}(D)$ at rest, immediately after exercise (after-ex), and after $60 \mathrm{~s}$ of passive recovery $(+60 \mathrm{~s})$ from $\mathrm{CIT}_{45}$ before and after $5 \mathrm{wk}$ of training. Values are means $+\mathrm{SE}$ $(n=6$, except for $+60 \mathrm{~s}$ lactate, where $n=5)$. *Significantly different from pretraining $(P<0.05)$. $\dagger$ Significantly different from rest $(P<0.05)$. $₫$ Significantly different from after-ex $(P<0.05)$. 


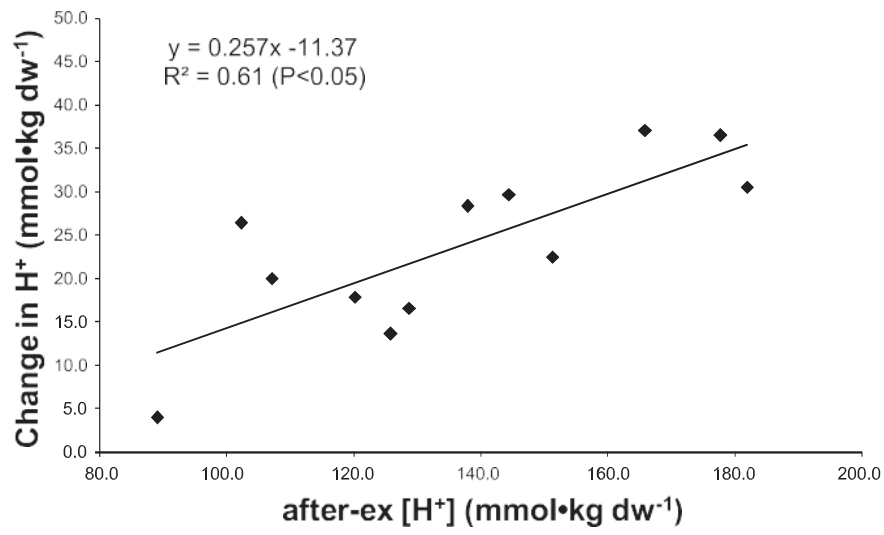

Fig. 4. Relationship between after-exercise $\mathrm{H}^{+}$and decrease in muscle $\mathrm{H}^{+}$ concentration $\left(\left[\mathrm{H}^{+}\right]\right)$during the $60 \mathrm{~s}$ after exercise. Data include pre- and posttraining data for 6 subjects (i.e., $n=12$ ).

$\mathrm{H}^{+}$and $\mathrm{j}^{3} \mathrm{~m}_{\text {in vitro }}(r=0.48, P>0.05)$. Furthermore, the relationship between the postexercise $\mathrm{H}^{+}$and the decrease in muscle $\mathrm{H}^{+}$remained significant $(r=0.70, P<0.05)$, even when the influence of $\mathrm{j} \mathrm{m}_{\text {in vitro }}$ on the decrease in muscle $\mathrm{H}^{+}$ during recovery was separated out.

\section{Plasma Lactate Concentration and $\mathrm{pH}$}

Plasma lactate and $\mathrm{pH}$ data measured before and after the 45-s cycle test before and after training are summarized in Fig. 5. After training, there was a significant decrease in plasma lactate concentration immediately after exercise $(P=$ $0.04)$ and 3 min after exercise $(P=0.03)$, but not 5 min after exercise $(P=0.08)$; there was no significant change in plasma $\mathrm{pH}$ at any time point $(P=0.07-0.13)$.

\section{DISCUSSION}

\section{Main Findings}

This is the first study to investigate training-induced changes in $\mathrm{j} 3 \mathrm{~m}_{\text {in vitro, }}$ MCT1, MCT4, and muscle lactate/ $\mathrm{H}^{+}$accumulation after high-intensity exercise in untrained women. The major finding was that high-intensity interval training, interspersed with short recovery periods, was associated with a significant decrease in $\mathrm{j} 3 \mathrm{~m}_{\text {in }}$ vitro without a significant change in MCT1 or MCT4 relative abundance in resting muscle. After training, reductions in muscle lactate and $\mathrm{H}^{+}$accumulation were observed in response to the same absolute workload. There was also a significantly smaller decrease in muscle $\mathrm{H}^{+}$, but not muscle lactate, in the first $60 \mathrm{~s}$ after exercise following training. Thus these findings allow a discussion about the importance of the local formation of $\mathrm{H}^{+}$and/or lactate within the skeletal muscle during exercise as an important stimulus to induce adaptations in $\mathrm{j} 3 \mathrm{~m}_{\text {in }}$ vitro, MCT1, and MCT4 and changes in muscle metabolites during recovery from intense exercise. These results have implications for the design of exercise interventions to modify these characteristics.

Effects of Training on $\mathrm{J}^{3} m_{\text {in }}$ vitro and MCT

\section{Relative Abundance}

Consistent with our previous research (15), high-intensity interval training $\left(6-12,2\right.$-min intervals at $\left.\$ 100 \% \dot{\mathrm{V}}_{2} \max \right)$, with short rest periods, resulted in a significant decrease in j3min vitro, which was observed in all subjects (Fig. 2). This result is likely to be due to a decrease in the intracellular buffers that are measured using the in vitro titration technique (i.e., phosphate, protein, and dipeptides within the muscle) (33). Our previous research (15) indicates that a decrease in muscle carnosine content is not the cause of the decrease in $j 3 \mathrm{~m}_{\text {in }}$ vitro. Furthermore, although we did not measure the content of other phosphate-bound compounds or the total adenine nucleotide concentration, the absence of changes in resting ATP or PCr after training suggests that the decrease in $\mathrm{j} 3 \mathrm{~m}_{\text {in }}$ vitro was not due to changes in intracellular phosphate. Therefore, the decrease in $\mathrm{j} 3 \mathrm{~m}_{\text {in vitro }}$ may be related to a decrease in intracellular protein buffering as a result of the large acidic load during training $(\mathrm{pH}$ $<6.8)(9,10)$ and/or the cumulative effect of repeated, transient decreases in intracellular protein buffering during the high-intensity training sessions (3).

Although $\mathrm{H}^{+}$can be buffered intracellularly, sarcolemmal lactate transporters also have an important role in the regulation of intracellular $\mathrm{pH}$ during high-intensity exercise (29). In the present study, there was no significant change in resting MCT1 or MCT4 relative abundance after training. The lack of change in MCT4 is consistent with the observation that MCT4 has typically been shown to be less sensitive to training than MCT1. Furthermore, significant changes in MCT4 in response to high-intensity training were not observed in two previous studies $(31,35)$. However, the absence of a significant change in MCT1 is in contrast to previous research that has reported significant increases after low-intensity (30), moderate-intensity $(6,11)$, and high-intensity $(7,31)$ training.

The most likely explanation for our contrasting results is our novel training protocol: this is the first study to use a training program consisting of relatively long, high-intensity intervals $\left(120 \mathrm{~s}\right.$ at $\left.100 \% \dot{\mathrm{V}}_{\mathrm{O} 2 \mathrm{max}}\right)$ interspersed with short $(60-\mathrm{s})$ rest

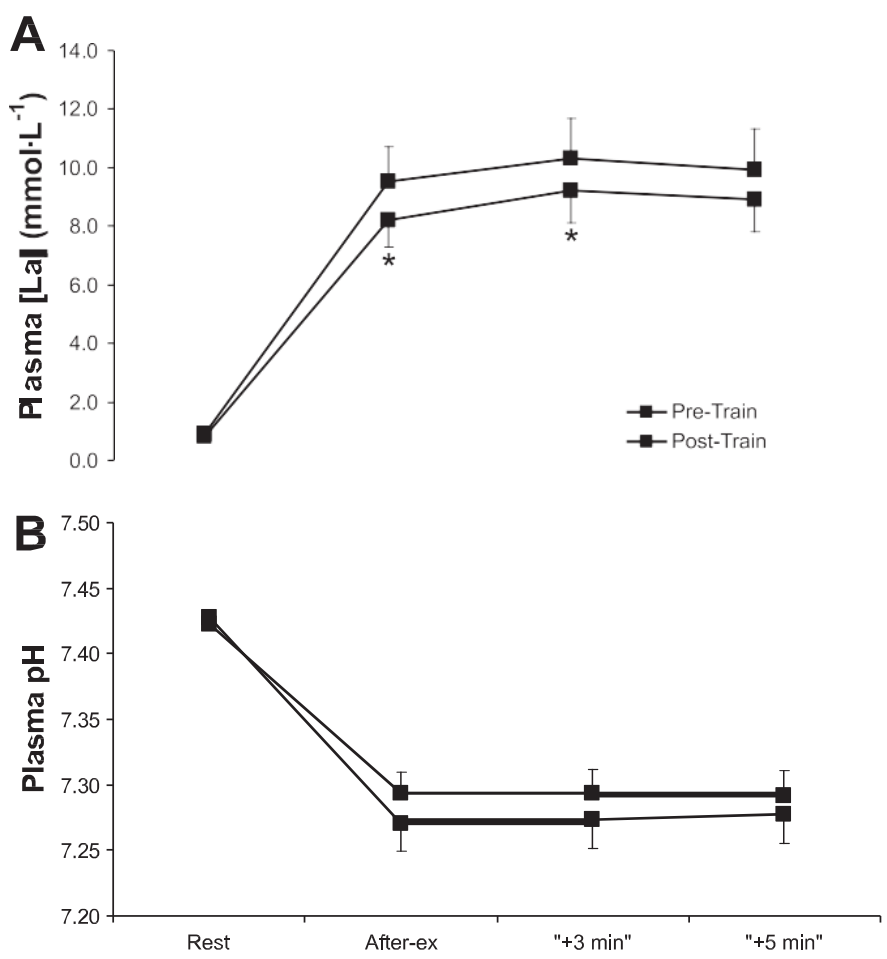

Fig. 5. Plasma lactate $(A)$ and $\mathrm{pH}(B)$ before and after 45 -s cycle test before and after training. *Significantly different from posttraining $(P<0.05)$. 
periods (i.e., 2:1 work-to-rest ratio). In previous intervaltraining studies, the work intervals were shorter $(30-60 \mathrm{~s})$ and the rest periods between high-intensity intervals were $90-180$ s (i.e., : S1:2 work-to-rest ratio) $(31,32,38)$. A longer rest period between high-intensity intervals allows greater removal of lactate and $\mathrm{H}^{+}$before subsequent intervals (42). Thus the muscle lactate and $\mathrm{H}^{+}$accumulation during training was greater in our study than in previous training studies that reported increases in MCT. This is supported by our generally much higher blood lactate levels during training. Although Mohr et al. (35) reported modest increases in MCT1, but not MCT4, in response to interval training that elicited blood lactate levels similar to those reported in the present study ( $14-17 \mathrm{mmol} / \mathrm{l}$ ), their muscle $\mathrm{pH}$ values during training were higher than those measured in the present study (6.98 vs. 6.81). Thus, contrary to previous suggestions $(13,31,50)$, the results of the present study suggest that increases in MCT relative abundance are not linked to the degree of muscle lactate and $\mathrm{H}^{+}$accumulation during training.

The nonsignificant changes in MCT relative abundance in response to training that produce large changes in muscle lactate are at odds with the results of a tissue culture study demonstrating that the addition of lactate anions can increase MCT1 mRNA and protein expression in L6 cells (23). However, one important difference between in vivo and tissue culture studies is that, in vivo, muscle contraction is also accompanied by the formation of $\mathrm{H}^{+}$(and other potential metabolic stimuli). These other stimuli may have contrasting effects on the intracellular signaling pathways responsible for increases in protein synthesis. For example, metabolically induced acidosis has previously been shown to result in an increase in the rate of amino acid oxidation and protein breakdown and a decrease in protein synthesis rate $(9,10)$. Thus, although lactate may be an important metabolic trigger for MCT1 gene expression, the results of this and other studies (35) suggest that it is not the degree of lactate and $\mathrm{H}^{+}$ accumulation that is the most important factor regulating the synthesis of this protein in contracting muscle. This has important implications for the design of exercise interventions to modify MCT relative abundance.

The absence of training-induced changes in MCT relative abundance in the present study may also be related to the sex of our subjects (female). Despite limited research, sex has been reported to exert a strong influence on gene expression (41) and, also, to influence changes in adipocyte proteins after significant weight reduction (19). This is the first study, to our knowledge, to investigate training-induced changes in MCT relative abundance in untrained women. However, it has previously been reported that interval training did not increase lactate transport capacity in female rats (40). These results may be related to the observation that testosterone has been shown to induce an increase in MCT1 and MCT4 proteins in skeletal muscle (16). Direct measurement of changes in MCT relative abundance in males and females exposed to the same training stimulus is required to test the hypothesis that sex influences training-induced changes in MCT proteins. Nonetheless, these results raise the possibility that different types of training may be required to alter MCT relative abundance in males and females.

\section{Muscle Lactate and $\mathrm{H}^{+}$}

Despite no change in MCT relative abundance, we observed the typical reductions in muscle lactate and $\mathrm{H}^{+}$accumulation that have been observed in previous studies after submaximal $(6,31,32)$ and supramaximal (22) exercise training. These changes have predominantly been attributed to reductions in lactate production and/or increases in lactate removal (37). The improvements in aerobic fitness $\left(10-13 \%\right.$ increase in $\dot{\mathrm{V}}_{2} \max$ and lactate threshold) suggest a decrease in anaerobic metabolism related to an improved potential for aerobic metabolism (24). Similar improvements in aerobic fitness have previously been associated with an increased aerobic contribution to supramaximal exercise $(12,13,49)$. In addition, attenuated muscle glycogenolysis has been reported after endurance training $(21,22)$. A decrease in anaerobic glycogenolysis (nonmitochondrial ATP turnover) will result in a decrease in $\mathrm{H}^{+}$and lactate production, as increased lactate accumulation coincides with cellular acidosis $(39,42)$, as verified by the results of the present study $(r=0.88, P<0.05)$. Thus an increased aerobic contribution and a decreased anaerobic contribution are likely to have contributed to the decreased postexercise lactate and $\mathrm{H}^{+}$values after training in the present study.

After training, there was no significant change in the decrease in muscle lactate content during the first $60 \mathrm{~s}$ after exercise. This contrasts with the results of previous interval training studies that have reported greater posttraining decreases in muscle lactate during the first $3-5$ min of recovery after exercise $(35,43)$. However, it is difficult to interpret these findings, as changes in muscle lactate were examined while the subjects performed more work (and produced more lactate) after training. It is well established that lactate- $\mathrm{H}^{+}$cotransport is driven by the lactate gradient across the sarcolemma (29). Furthermore, it appears that most of the greater muscle lactate decrease reported by Mohr et al. (35) can be explained by the increase in postexercise lactate after training (Fig. 6). Thus our results suggest that training that induces large changes in muscle lactate does not necessarily induce adaptations that lead to a greater decrease in muscle lactate after intense exercise.

Consistent with previous research, the decrease in muscle $\mathrm{H}^{+}$during recovery was greater than the decrease in muscle lactate $\left(\mathrm{H}^{+}\right.$-to-lactate ratio of 1.9 to 1.2 pre- to posttraining). These values are close to the $\mathrm{H}^{+}$-to-lactate ratio of 1.6 obtained with the NMR technique and human muscle (36). The greater

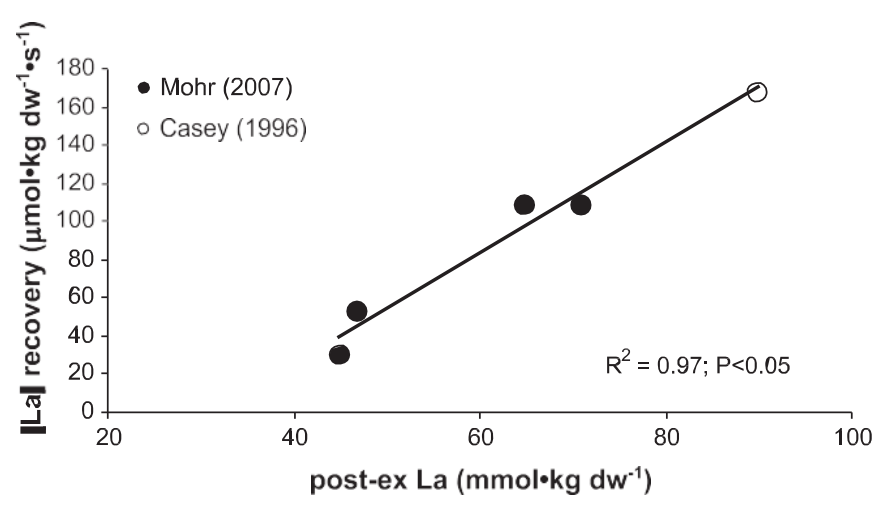

Fig. 6. Relationship between postexercise lactate (La) and decrease in muscle lactate concentration ([La]) during $3 \mathrm{~min}$ of passive rest following exercise. Data are based on mean results reported by Casey et al. (8) and Mohr et al. (35). 
postexercise decrease in $\mathrm{H}^{+}$than in lactate can be explained by the release of $\mathrm{H}^{+}$from muscle fibers, by not only the lactate $-\mathrm{H}^{+}$transporter, but also by the $\mathrm{Na} / \mathrm{H}^{+}$exchanger and $\mathrm{HCO}_{3}^{-}$-dependent systems (28). However, a novel finding of the present study was the significantly smaller postexercise decrease in muscle $\mathrm{H}^{+}$after training $(25.7$ vs. $17.8 \mathrm{nmol} / \mathrm{l}, P<$ $0.05)$. Our results suggest that this is not related to the decrease

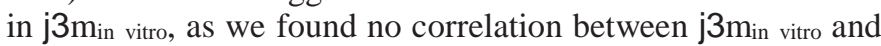
the decrease in muscle $\mathrm{H}^{+}$. Instead, the smaller postexercise decrease in muscle $\mathrm{H}^{+}$was correlated with the lower $\mathrm{H}^{+}$ accumulation during exercise (Fig. 4).

In addition, the greater rate of $\mathrm{PCr}$ resynthesis after training (and subsequent release of $\mathrm{H}^{+}$) would have contributed to the smaller decrease in muscle $\mathrm{H}^{+}$after training. As $\mathrm{p} K$ a values for $\mathrm{PCr}$ and $\mathrm{P}_{\mathrm{i}}$ are 4.5 and 6.8, respectively, it can be calculated that, at a muscle $\mathrm{pH}$ of $6.9,840 \%$ of the smaller decrease in muscle $\mathrm{H}^{+}$in the present study can be attributed to the increased rate of $\mathrm{PCr}$ resynthesis (25). Thus our results indicate that training that results in a decrease in $\mathrm{H}^{+}$accumulation and an increase in the rate of $\mathrm{PCr}$ resynthesis can actually lower the decrease in muscle $\mathrm{H}^{+}$following supramaximal exercise.

\section{Perspectives and Significance}

The local formation of $\mathrm{H}^{+}$and/or lactate within the skeletal muscle during exercise has been proposed to be an important stimulus for adaptations of the muscle $\mathrm{pH}$-regulating systems $(13,31,50)$. However, an important finding of the present study is that changes in $\mathrm{j} 3 \mathrm{~m}_{\mathrm{in}}$ vitro and MCT relative abundance do not appear to be linked to the degree of muscle lactate and $\mathrm{H}^{+}$accumulation during training. Further research is therefore required to understand the complex intramuscular signals that are responsible for training-induced changes in the $\mathrm{pH}$-regulating systems of the muscle; this has important implications for the design of exercise interventions to modify these characteristics. The smaller decrease in muscle $\mathrm{H}^{+}$during the recovery from the $\mathrm{CIT}_{45}$ is also a novel finding and suggests that training that results in a decrease in $\mathrm{H}^{+}$accumulation and an increase in the rate of $\mathrm{PCr}$ resynthesis can actually reduce the decrease in muscle $\mathrm{H}^{+}$following supramaximal exercise. This has interesting implications for the design of training programs to improve repeated-sprint performance, as although an increase in $\mathrm{PCr}$ resynthesis should improve performance (5), less removal of $\mathrm{H}^{+}$during the recovery periods between repeated sprints has the potential to impair performance $(2,20)$.

\section{ACKNOWLEDGMENTS}

We thank the subjects for their commitment to the challenging training program and for their maximal effort during all tests. We also thank Prof. Dominique Mornet and Gerald Hugon for the production of MCT1 and MCT4 antibodies.

\section{REFERENCES}

1. Arthur P, Hochachka PW. Automated analysis of cellular metabolites at nanomolar to micromolar concentrations using bioluminescent methods. Anal Biochem 227: 281-284, 1995.

2. Bishop D, Edge J, Davis C, Goodman C. Induced metabolic alkalosis affects muscle metabolism and repeated-sprint ability. Med Sci Sports Exerc 36: 807-813, 2004.

3. Bishop D, Edge J, Thomas C, Mercier J. High-intensity exercise acutely decreases the membrane content of MCT1 and MCT4 and buffer capacity in human skeletal muscle. J Appl Physiol 102: 616-621, 2007.

4. Bishop D, Jenkins DG, Mackinnon LT. The relationship between plasma lactate parameters, $\mathrm{W}_{\text {peak }}$ and 1-h cycling performance in women. Med Sci Sports Exerc 30: 1270-1275, 1998.
5. Bogdanis GC, Nevill ME, Boobis LH, Lakomy HK, Nevill AM. Recovery of power output and muscle metabolites following $30 \mathrm{~s}$ of maximal sprint cycling in man. $J$ Physiol 482: 467-480, 1995.

6. Bonen A, McCullagh KJA, Putman CT, Hultman E, Jones NL, Heigenhauser GJF. Short-term training increases human muscle MCT1 and femoral venous lactate in relation to muscle lactate. Am J Physiol Endocrinol Metab 274: E102-E107, 1998.

7. Burgomaster KA, Cermak NM, Phillips SM, Benton CR, Bonen A, Gibala MJ. Divergent response of metabolite transport proteins in human skeletal muscle after sprint interval training and detraining. Am J Physiol Regul Integr Comp Physiol 292: R1970-R1976, 2007.

8. Casey A, Constantin-Teodosiu D, Howell S, Hultman E, Greenhaff PL. Metabolic responses of type I and II muscle fibers during repeated bouts of maximal exercise in humans. Am J Physiol Endocrinol Metab 271: E38-E43, 1996.

9. Caso G, Garlick BA, Casella GA, Sasvary D, Garlick PJ. Acute metabolic acidosis inhibits muscle protein synthesis in rats. Am J Physiol Endocrinol Metab 287: E90-E96, 2004.

10. Caso G, Garlick PJ. Control of muscle protein kinetics by acid-base balance. Curr Opin Clin Nutr Metab Care 8: 73-76, 2005.

11. Dubouchaud H, Butterfield GE, Wolfel EE, Bergman BC, Brooks GA. Endurance training, expression, and physiology of LDH, MCT1, and MCT4 in human skeletal muscle. Am J Physiol Endocrinol Metab 278: E571-E579, 2000.

12. Duffield R, Edge J, Bishop D. Effects of high-intensity interval training on the $\dot{\mathrm{V}}_{2}$ response during severe exercise. J Sci Med Sport: 249-255, 2006.

13. Edge J, Bishop D, Goodman C. Effects of chronic $\mathrm{NaHCO}_{3}$ ingestion during interval training on changes to muscle buffer capacity, metabolism, and short-term endurance performance. J Appl Physiol 101: 918-925, 2006.

14. Edge J, Bishop D, Goodman C. The effects of training intensity on muscle buffer capacity in females. Eur J Appl Physiol 96: 97-105, 2006.

15. Edge J, Goodman C, Bishop D. Very high-intensity interval training with short rest periods decreases muscle buffer capacity. Proc ECSS Conf Laussane, 2006, p. 477.

16. Enoki T, Yoshida Y, Lally J, Hatta H, Bonen A. Testosterone increases lactate transport, monocarboxylate transporter (MCT) 1 and MCT4 in rat skeletal muscle. J Physiol 577: 433-443, 2006.

17. Eversten F, Medbo JI, Bonen A. Effect of training intensity on muscle lactate transporters and lactate threshold of cross-country skiers. Acta Physiol Scand 173: 195-205, 2001.

18. Favero TG, Zable AC, Bowman MB, Thompson A, Abramson JJ. Metabolic end products inhibit sarcoplasmic reticulum $\mathrm{Ca}^{2+}$ release and $\left[{ }^{3} \mathrm{H}\right]$ ryanodine binding. J Appl Physiol 78: 1665-1672, 1995.

19. Fisher R, Hoffstedt J, Hotamisligil G, Thorne A, Ryden M. Effects of obesity and weight loss on the expression of proteins involved in fatty acid metabolism in human adipose tissue. Int J Obes 26: 1379-1385, 2002.

20. Gaitanos GC, Williams C, Boobis LH, Brooks S. Human muscle metabolism during intermittent maximal exercise. J Appl Physiol 75: 712-719, 1993.

21. Green HJ, Helyar R, Ball-Burnett M, Kowalchuk N, Symon S, Farrance B. Metabolic adaptations to training precede changes in muscle mitochondrial capacity. J Appl Physiol 72: 484-491, 1992.

22. Harmer AR, McKenna MJ, Sutton JR, Snow RJ, Ruell PA, Booth J, Thompson MW, Mackay NA, Stathis CG, Crameri RM, Carey MF, Eager DM. Skeletal muscle metabolic and ionic adaptations during intense exercise following sprint training in humans. J Appl Physiol 89: 1793-1803, 2000.

23. Hashimoto T, Hussien R, Oommen S, Gohil K, Brooks GA. Lactate sensitive transcription factor network in L6 cells: activation of MCT1 and mitochondrial biogenesis. FASEB J 21: 2602-2612, 2007.

24. Holloszy JO, Coyle EF. Adaptations of skeletal muscle to endurance exercise and their metabolic consequences. J Appl Physiol 56: 831-838, 1984.

25. Hultman E, Sahlin K. Acid-base balance during exercise. Exerc Sport Sci Rev 8: 41-128, 1980.

26. Jubrias SA, Crowther GJ, Shankland EG, Gronka RK, Conley KE. Acidosis inhibits oxidative phosphorylation in contracting human skeletal muscle in vivo. J Physiol 533: 589-599, 2003.

27. Juel C. Muscle pH regulation: role of training. Acta Physiol Scand 162: 359-366, 1998. 
28. Juel C. Regulation of cellular $\mathrm{pH}$ in skeletal muscle fiber types, studied with sarcolemmal giant vesicles obtained from rat muscles. Biochim Biophys Acta 1265: 127-132, 1995.

29. Juel C, Halestrap A. Lactate transport in skeletal muscle-role and regulation of the monocarboxylate transporter. J Physiol 517: 633-642, 1999.

30. Juel C, Holten MK, Dela F. Effects of strength training on muscle lactate release and MCT1 and MCT4 content in healthy and type 2 diabetic humans. J Physiol 556: 297-304, 2004.

31. Juel C, Klarskov C, Nielsen JJ, Krustrup P, Mohr M, Bangsbo J. Effect of high-intensity intermittent training on lactate and $\mathrm{H}^{+}$release from human skeletal muscle. Am J Physiol Endocrinol Metab 286 : E245-E251, 2004.

32. Krustrup P, Mohr M, Nybo L, Jensen JM, Nielsen JJ, Bangsbo J. The Yo-Yo IR2 test: physiological response, reliability, and application to elite soccer. Med Sci Sports Exerc 38: 1666-1673, 2006.

33. Mannion AF, Jakeman PM, Willan PLT. Determination of human skeletal muscle buffer value by homogenate technique: methods of measurement. J Appl Physiol 75: 1412-1418, 1993.

34. McCullagh KJ, Poole RC, Halestrap AP, O'Brien M, Bonen A. Role of the lactate transporter (MCT1) in skeletal muscles. Am J Physiol Endocrinol Metab 271: E143-E150, 1996.

35. Mohr M, Krustrup P, Nielsen JJ, Nybo L, Rasmussen MK, Juel C, Bangsbo J. Effect of two different intense training regimens on skeletal muscle ion transport proteins and fatigue development. Am J Physiol Regul Integr Comp Physiol 292: R1594-R1602, 2007.

36. Pan J, Hamm J, Hetherington H, Rothman J, Shulman R. Correlation of lactate and $\mathrm{pH}$ in human skeletal muscle after exercise by ${ }^{1} \mathrm{H}$ NMR. Magn Reson Med 20: 57-65, 1991.

37. Phillips SM, Green HJ, Tarnopolsky MA, Grant SM. Increased clearance of lactate after short-term training in men. J Appl Physiol 79: 18621869, 1995.

38. Pilegaard H, Domino K, Noland T, Juel C, Hellsten Y, Halestrap AP, Bangsbo J. Effect of high-intensity exercise training on lactate $/ \mathrm{H}^{+}$transport capacity in human skeletal muscle. Am J Physiol Endocrinol Metab 276: E255-E261, 1999.

39. Robergs RA, Ghiasvand F, Parker D. Lingering construct of lactic acidosis. Am J Physiol Regul Integr Comp Physiol 289: R502-R516, 2005.
40. Roth DA, Brooks GA. Training does not affect zero-trans lactate transport across mixed rat skeletal muscle sarcolemmal vesicles. J Appl Physiol 75: 1559-1565, 1993.

41. Roth S, Ferrell R, Peters D, Metter E, Hurley B, Rogers M. Influence of age, sex, and strength training on human muscle gene expression determined by microarray. Physiol Genomics 10: 181-190, 2002.

42. Sahlin K, Harris RC, Nylind B, Hultman E. Lactate content and $\mathrm{pH}$ in muscle samples obtained after dynamic exercise. Pflügers Arch 367: 143-149, 1976.

43. Sharp RL, Costill DL, Fink WJ, King DS. Effects of eights weeks of bicycle ergometer sprint training on human muscle buffer capacity. Int J Sports Med 7: 13-17, 1986.

44. Spriet LL, Lindinger MI, McKelvie RS, Heigenhauser GJF, Jones NL. Muscle glycogenolysis and $\mathrm{H}^{+}$concentration during maximal intermittent cycling. J Appl Physiol 66: 8-13, 1989.

45. Srere P. Citrate synthase. Methods Enzymol 13: 3-5, 1969.

46. Street D, Nielsen JJ, Bangsbo J, Juel C. Metabolic alkalosis reduces exercise-induced acidosis and potassium accumulation in human skeletal muscle interstitium. J Physiol 566: 481-489, 2005.

47. Thomas C, Bishop D, Moore-Morris T, Mercier J. Effects of highintensity training on MCT1, MCT4, and NBC expressions in rat skeletal muscles: influence of chronic metabolic alkalosis. Am J Physiol Endocrinol Metab 293: E916-E922, 2007.

48. Thomas C, Perrey S, Lambert K, Hugon G, Mornet D, Mercier J. Monocarboxylate transporters, blood lactate removal after supramaximal exercise, and fatigue indexes in humans. J Appl Physiol 98: 804-809, 2005.

49. Weber CL, Schneider DA. Increases in maximal accumulated oxygen deficit after high-intensity interval training are not gender dependent. J Appl Physiol 92: 1795-1801, 2002.

50. Weston AR, Myburgh KH, Lindsay FH, Dennis SC, Noakes TD, Hawley JA. Skeletal muscle buffering capacity and endurance performance after high-intensity interval training by well-trained cyclists. Eur J Appl Physiol 75: 7-13, 1997.

51. Wilson MC, Jackson VN, Heddle C, Price NT, Pilegaard H, Juel C, Bonen A, Montgomery I, Hutter OF, Halestrap AP. Lactic acid efflux from white skeletal muscle is catalyzed by the monocarboxylate transporter isoform MCT3. J Biol Chem 273: 15920-15926, 1998. 